\title{
Effects of Canada's Increasing Linguistic and Cultural Diversity on Educational Policy, Programming and Pedagogy
}

\author{
Michelle Lam \\ Brandon University \\ lamm@brandonu.ca
}

\begin{abstract}
Canada's linguistic and cultural diversity is steadily increasing. In order to ensure that the education provided to students in Canadian classrooms is relevant, future-focused, and honouring to the depth of linguistic and cultural resources represented within classrooms, it is necessary for teachers and policy-makers to have a strong understanding of how English as an additional language (EAL) students learn language and literacy, and how they can enrich the learning environment of the classroom as a whole. This article describes the effects of Canada's increasing diversity on educational policy, programing, and pedagogy. Beginning with an exploration of current policy trends and an overview of programming responses, the article then concludes with promising classroom and pedagogical approaches.
\end{abstract}

\section{Context}

In Canada, 22.9\% of people report a "mother tongue" that is neither English nor French (Government of Canada, 2017). Within Canadian primary and secondary schools, there were 4.75 million students enrolled in the 2015/2016 school year (Statista, 2018), and 2.2 million children under age 15 who were foreign-born or who had at least one foreign-born parent (Government of Canada, 2017). 37.5\% of all Canadian children have an immigrant background (Government of Canada, 2017). These statistics point towards large numbers of students in Canadian schools who have a depth of linguistic resources and repertoire, which has implications for educational policy, programming, and pedagogy.

\section{Terminology}

Language is a complex concept. It can encompass the social aspect of its construction, including social experiences and identities (Atkinson et al., 2016). At the same time, despite fluid and changing social boundaries, language is also used by nations, communities, and individuals as a more rigid symbol of value, identity, and distinctiveness (Creese \& Blackledge, 2011). Language then can be defined broadly to include "cognition, emotions, consciousness, experience, embodiment, brain, self, human interaction, society, culture, mediation, instruction, and history in rich, complex, and dynamic ways" (Atkinson et al., 2016, p. 39; Dagenais, Toohey, Bennett Fox, \& Singh, 2017).

Literacy is not synonymous with French or English literacy alone, nor is it limited to reading and writing, but it involves different languages and multiple forms (Ntelioglou, Fannin, Montanera, \& Cummins, 2014). Effective literacy education, then, is not only about promoting reading and writing, but it involves a broader definition which includes cultural knowledge, oral and written Journal of Contemporary Issues in Education, 2019, 14(2), pp. 16-32. doi: 10.20355/jcie29370 ISSN 1718-4770 
language, collaborative empowerment for linguistic minority students, and social justice (Cummins, 2014b). Redefining literacy in in this way includes the deep repository of knowledge within cultural communities and can give students a foundation from which they can succeed academically (Cummins, 2014b).

In this article, I will refer to policy in a broad sense of the word, to refer not only to government or educational policy documents, but rather "constellations of official pronouncements, curriculum documents and professional discussions that eventually distil into specific views and/or courses of action" (Leung, 2016, p. 159).

I recognize that many of the terms used to label and define language learners can be problematic. Even the term English language learners can become one large category, obscuring differences in backgrounds, goals, and abilities (Duff, 2015). The move from 'English as a Second Language' to 'English as an Additional Language" reflects the acknowledgement that students may have more than one language (Leung, 2016), but it is still unable to differentiate in any meaningful way. In this paper I will attempt to reflect the language of the original authors.

\section{Policy Debates}

Education in Canada falls under provincial jurisdiction, which means that specific policies regarding language teaching differ from province to province (Cummins, 2014a). Below I will explore several broad themes that cross provincial borders.

\section{Teacher Preparation for EAL Students}

At the present time, teachers are not professionally prepared to meet the needs of students with vastly different levels of English proficiency (Haneda \& Wells, 2012). Despite this clear gap, "educational policies and structures (e.g., teacher education) across Canada have articulated no expectation or requirement that mainstream teachers should have any knowledge regarding appropriate ways of scaffolding instruction for second language learners" (Cummins, 2014a, p. 4). Similarly, administrators are not expected to understand the process of language acquisition, have a positive understanding of students' home languages, nor to be able to lead within a linguistically and culturally diverse school (Cummins, 2014a; Ntelioglou et al., 2014). In other words, we have a "teacher population that is primarily White and culturally isolated, a student population that is increasingly diverse, and educational outcomes that reflect persistent inequalities across racial differences" (Howard, 2016, p. 5).

School systems across Canada need to analyze the policies and practices they enact, to ensure that the values they proclaim are embodied within those policies and practices. Until then, there remains a "significant gulf between children's linguistic capital and the language priorities of formal education" (Lotherington, 2013, p. 620), and teachers are the ones who end up trying to bridge the gap. The implication is that teachers are teaching students who are similar to them, but that is not the reality:

Teachers are squeezed, trying to meet formal expectations that students communicate according to provincial or regional standards and in official national languages, find common ground in their classrooms of learners of mixed backgrounds and abilities, sort out which digital tools are accessible and helpful for contemporary communication, and

Journal of Contemporary Issues in Education, 2019, 14(2), pp. 16-32. 
mollify parents expecting constant and instant English for their children, while trying to experiment towards the repeated refrain that formal education should teach towards creativity and innovation, not fixed subject matter. This is a very tall order. (Lotherington, 2017, p. 9)

\section{Native-Speaker Norms}

One of the challenges in language policy is uncovering and dismantling native-speaker norms, which demands EAL students adopt the intonation, rhythm, and pitch of the mainstream (Atkinson et al., 2016; Leung, 2016), and which assumes that learning another language is simply adding a separate monolingual code rather than acknowledging the complexity of bi/multilingualism (Cummins, 2017; García, 2008). Assuming monolingualism as the default position leads to policies and programming models which posit that "learners should develop the pure competence of two monolinguals in one head" (Atkinson et al., 2016) and ban behaviours and practices that serve to promote bi-/multilingualism. Multilingual competence looks different from monolingual competence, and the two develop differently, progress differently, and have different measures for success (Atkinson et al., 2016).

Programs which are built on native-speaker norms, or which have native-speaker norms as their goal, tend to diminish the value of multilingualism rather than setting goals for students which aim to "enhance their linguistic repertoire rather than replace or diminish the value of other languages" (Manitoba Education and Training, 2011, p. 17). The result of this mentality is bilingual children who are "becoming less than they were, not more than they were" (Ntelioglou et al., 2014, p. 1).

Although Canada's increasing linguistic and cultural diversity is resulting in increasing multilingual norms, secondary students must still operate within a context that is increasingly performance-based, with standardized testing conducted in the majority language. This points to an "access paradox" (Janks, 2004, p. 33) where providing focused instruction in the majority language serves to perpetuate its dominance, while on the other hand supporting minority languages can perpetuate marginalization in a system that recognizes and rewards linguistic ability in the majority language. This problematic paradox means that approaches to language education must be practical, respectful of and in collaboration with the varied wishes of parents and community members, and framed with the goals of facilitating access to higher education and workplace opportunities. At the same time, it must take a critical view of majority languages' dominance, recognizing that dominant does not mean superior. This is not an easy balance.

\section{Deficit Mentality}

The construction of language learning students as Other, or as "deficient and struggling to catch up to an idealized English-speaking norm" (Stille \& Cummins, 2013, p. 631), takes place within a larger political and cultural climate that may include a view that newcomer children represent a "threat to 'standards' and to the quality of education in schools" (Leung, 2016, p. 160). Bi/multilingual students within this climate are seen as "deviant and in need of 'fixing' by educational institutions" (Dagenais et al., 2017, p. 266). Opposite this view is the notion that linguistic diversity is a strength rather than a threat (Leung, 2016; Stille \& Cummins, 2013). In 
the words of Lotherington (2017), "the languages children import into the country (and classroom) constitute an asset in our global era, not a problem, and they should be creatively incorporated" (p. 6).

Students may internalize this deficit mentality (Atkinson et al., 2016), as in the case of students involved in a family stories project who initially believed their grandparents did not have any stories to tell (Marshall \& Toohey, 2010), or in the case of EAL students feeling embarrassed to work with a partner or in a group because they felt they would be a burden (Toohey, 1998), or in the case of Roma students who had developed "learned helplessness" (Ntelioglou et al., 2014, p. 6 ) and believed they had nothing to contribute. Students may feel ambivalence, or even shame about their home languages (Cummins, 2014b). Students may also feel caught between their own identities of competent, proficient, global, transnational multilinguals and the ascribed identities of struggling new immigrants learning language (Duff, 2015).

This deficit mentality may extend to the home life as well. Parents may also have the belief that their home language is not as important as English, and they may not support projects or practices which spend classroom time on other languages (Dagenais et al., 2017). Students may also view the languages of their parents from this deficit mentality (Duff, 2015).

\section{Differing Cultural Expectations}

Cultural expectations between home and school environments can be different. There may be tensions between curriculum expectations within a Eurocentric framework and community practices that conflict with those practices or value other emphases (Leung, 2016). There may be linguistic tensions, as parents and students negotiate conflicting ideologies and desires around language (Atkinson et al., 2016). In discussing these conflicts and mismatched expectations, Duff (2015) points out that they deal with issues not only of "surviving and thriving but also belonging" (p. 58). Issues related to belonging and identity must go beyond celebrating cultural differences to acknowledging the very real impact that unequal power relations and systems of inequity perpetuate (Gorski, 2008).

These differing cultural expectations around education, what is important in education, and what language(s) is/are valuable can be both areas of conflict and areas of potential learning. It is important to acknowledge that "culturally and linguistically diverse parents represent a significant source of support" (Ntelioglou et al., 2014, p. 2) and can be instrumental in the development of a students' bi-/multilingualism. They are also significant knowledge contributors who can contribute to stronger schools and education systems.

\section{Globalization}

The multilingualism of classrooms today are "enmeshed in globalization, technologization, and mobility" (Atkinson et al., 2016). What this means for students in Canada is that multilingualism is normal, identity is not geographically determined, and the dichotomy of a "language learner" and a "mainstream" student is questionable (Atkinson et al., 2016). Within this environment, "teachers are faced with nationally-focused curricular materials on social and political belonging with classes of superdiverse learners representing the globe who actively participate in social media spheres" (Lotherington, 2017, p. 4). In some cases, teachers or administrators may be 
operating from the idea that newcomers should permanently settle in Canada and seek to become as "Canadian" as possible, when many of these children and their parents may be seeking fully developed bi-/multilingualism and bi-/multiculturalism (Duff, 2015), may choose to migrate back "home" or elsewhere, or may choose a lifestyle of permanent mobility. Because of technology, popular culture, media, networking, and gaming spaces, these children may create third spaces (Lotherington, 2013) in which they neither identify with their parents' culture nor the culture of the mainstream classroom. They may find or develop a strong sense of identity and belonging within a community of diasporic, transnational, global citizens (Duff, 2015). These third spaces, however, can become insular communities which do not prepare students for power dynamics outside of high school, creating shock and disillusionment with the marginalization they experience in relation to the dominant groups and institutions in the workforce or higher education (Ali, 2008).

However, considering the super-diverse, multicultural communities formed in schools, EAL materials that are aimed towards assimilation and fostering citizenship within Canada are insufficient and problematic. Caricatured lessons set in iconic tourist sites must be replaced with deeper engagement that allows students to explore their identities, histories, and trajectories within their multilingual, transnational world (Duff, 2015).

\section{Sociological Dimensions}

Learning is not just the accumulation of knowledge, but it involves highly situated dimensions of belonging, doing, becoming, experiencing, developing, and transforming (Duff, 2017). Contact with more languages strengthens metalinguistic awareness (Chumak-Horbatsch, 2012; Naqvi, 2015) and increases language learning ability (Moore, 2010). Yet these strengths are not only cognitive and systematic functions; they also rely on social factors (Moore, 2010). Even very young children have agency to use language to navigate their social environments, including showing respect, belonging, identity, in-group allegiance, sharing secrets, legitimacy, maintaining face, and loyalty (Moore, 2010). Academic achievement is linked to negotiating these identities: "making friends, getting due respect, and establishing oneself as a full-fledged member of the school community" (Kanno, 1999, p. 127). This means that teachers need to send messages that strongly affirm personal worth and academic potential (Cummins, 2014b) and to dismantle "institutional violence of schooling in the form of literacy or language practices that often ignore, attempt to remediate, or devalue the lives and experiences of children and their families" (Marshall \& Toohey, 2010, p. 222).

Historically, power relationships played a significant and detrimental role in schooling in Canada (Cummins, 2014b). Today, students are not beaten for speaking their first language, but they may experience "benign neglect" (Cummins, 2014b, Ntelioglou et al., 2014) or other messages that communicate a lack of value. As Lotherington (2013) writes, "Languages are not social equals. Official, commercially viable, and civically responsive languages are prioritized in the classroom" (p. 619).

Communicating messages to multilingual students that value their languages requires thinking analytically about the relationship between power and schooling (Cummins, 2014b) and challenging the colonial legacy and current discourses of devaluation (Cummins, 2014b). Students who come from social groups that have been marginalized in wider society tend to Journal of Contemporary Issues in Education, 2019, 14(2), pp. 16-32. doi: 10.20355/jcie29370 ISSN 1718-4770 
experience higher percentages of academic failure, which shows that devaluing identity is related to underachievement (Ladson-Billings, 1995; Cummins, 2014b). The traditional approach has been to assimilate newcomers into the norms of the mainstream group, yet "the solution is not to 'integrate' them into the structure of oppression, but to transform that structure so that they can become 'beings for themselves"' (Freire, 1996, p. 74).

\section{Programming Models}

With these background challenges and opportunities in mind, I will explore different programming models for EAL instruction, focusing on their unique features, strengths, and challenges they may bring.

\section{Pull-Out Programs}

Pull-out programs, or programs which provide EAL instruction separately from regular classes, are built on the idea that providing focused language instruction helps to hasten the students' language acquisition. They also dilute the concentration of EAL learners in the classroom, serving to "spread the load" (Leung, 2016, p. 160) and promote faster assimilation.

While these programs may be favoured by teachers who feel overwhelmed and unprepared to support the needs of linguistically diverse students, pull-out programs operate on the assumption that "ESL teachers will take care of 'fixing' the language problems of English language learners" (Cummins, 2014a, p. 4), or that the "provision of instructional support for ELL [English language learners] students is the job of the ESL teacher" (Ntelioglou et al., 2014, p. 2). Pull-out programs have also been problematized because they may serve to promote "racial and linguistic segregation" (Leung, 2016, p. 160), cutting students off from the rest of the school and erecting barriers rather than removing them (Toohey, 1998).

Not only can pull-out programs be problematized for their social consequences, but they also do not recognize that language development is a "long-term process implicating all areas of the curriculum and that short-term intensive English language teaching can only serve as a very limited form of initial educational provision" (Leung, 2016, p. 161). Budgetary constraints usually prevent pull-out programs from developing to meet the long-term needs of students.

\section{Mainstreaming}

Mainstreaming, or including EAL students in the regular classroom, was developed in opposition to the separate provision model (Leung, 2016). It was based on the idea that learning language happens through meaningful communication (Krashen, 1982) and "active and meaningful use" (Leung, 2016, p. 162). Pedagogically, the communicative language teaching approach and Cummins's work distinguishing between basic communication ability and academic language proficiency (Cummins, 2014b) was key in promoting the practice of mainstreaming students (Leung, 2016). It was also advanced by the efforts to promote equal opportunities and to include linguistic diversity as an enrichment for learning (Leung, 2016).

One of the major challenges with mainstreaming is that teachers may not be equipped to work with linguistically diverse students or know how to include linguistic learning outcomes within their curriculum or lessons. Although the principle of learning English through participating in Journal of Contemporary Issues in Education, 2019, 14(2), pp. 16-32. doi: 10.20355/jcie29370 ISSN 1718-4770 
the "regular" curriculum is well-founded, "teacher diligence in its application is the main issue" (Leung, 2016, p. 164). Teachers may struggle to adapt instruction or provide strategies that can be tailored to meet the individual students' language needs (Manitoba Education and Training, 2011). Teachers are also not well equipped to differentiate between the process of learning a new language and learning disabilities (Manitoba Education and Training, 2011). Despite decades of research into language learning, "a large majority of teachers and administrators have not had opportunities to access the knowledge base regarding effective instruction for [immigrantbackground students] nor have they had opportunities for pre-service or in-service professional development regarding effective instructional practices" (Cummins, 2014a, p. 1).

Another challenge within school environments where standards are set outside of the school context is that all students may be required to meet common performance standards, regardless of individual circumstances. Ironically, to mitigate against the criticism that pulling out students to provide separate language instruction was a racist practice, the resulting mainstreaming model does not necessarily provide the equality envisaged, as the equality of entitlement narrative is replaced with a "neoliberal discourse that emphasize[s] competition as an organizing principle for society" (Leung, 2016, p. 171). Recognizing diversity can be "difficult in schools that have histories of and investments in standard languages and authorized knowledge" (Dagenais et al., 2017 , p. 263). Equality is defined as equal access to the same curriculum content and classroom, but this fails to consider the contextual nuances of teacher competence in working with language students, classroom power dynamics, social structures, and complex identity navigation. In other words, "it is inappropriate to set learning goals for which students do not have the necessary scaffolding" (Manitoba Education and Training, 2011, p. 13). These assessment challenges have been met in practice using shared supervision in open plan classrooms, assessment using a baseline done at entry, and the use of language portfolios (Leung, 2016). However, where standardized measures are in place, assessment remains a challenge.

Mainstreaming models can be supplemented with additional EAL support within the classroom, as in the push-in model, where co-teachers or EAL support staff assist the language learner within the regular classroom, or through sheltered instruction, where the teacher includes linguistic goals within the regular content classroom. Although these models have benefits, they may also serve to marginalize students even though they have not been physically segregated from the classroom, especially if the teachers are not equipped to work with linguistically diverse students. This marginalization can also occur within the culture of the classroom if teachers view students as language-deficient rather than viewing the cultural and linguistic resources that the student brings as strengths from which the entire class can benefit. For example, in China, children often start learning to read and write at the age of 2 or 3 and may arrive in Canadian kindergarten classrooms with strong backgrounds in literacy, yet teachers are often unaware of the potential and strengths of these multilingual, multiliterate learners (Moore, 2010). Worse, schools may view these students as "deviant" (Toohey, 1998, p. 78), requiring "normalization" (Waterhouse, 2004).

\section{Immersion}

In Canada, French and English are the official languages of instruction, and students may attend immersion schools which teach in one primary language with the other language taught as a subject area. For example, in Manitoba, French immersion schools use French as the language of Journal of Contemporary Issues in Education, 2019, 14(2), pp. 16-32. doi: 10.20355/jcie29370 ISSN 1718-4770

(c) Author(s), Creative Commons Attribution 4.0 (CC BY 4.0) licence http://ejournals.library.ualberta.ca/index.php/JCIE 
instruction and teach English Language Arts (ELA) as a subject area (Manitoba Education and Training, 2011). The difference between mainstreaming and immersion programs is that in Canadian immersion programs, the program was traditionally developed with the goal of promoting bilingualism (understood to mean French and English) by providing support for the students' first languages (Moore, 2010). Newcomer parents may enroll their children in French immersion schools, even if French is not one of the languages spoken at home. They may choose to do this for a variety of reasons, such as the belief that bilingualism in both French and English will give their children more power and social standing within Canada (Moore, 2010) or because they simply value bi-/multilingualism (Manitoba Education and Training, 2011).

Within immersion schools, many teachers, administrators, and parents consider "language separation the best practice for protecting and maintaining French in settings where English is dominant in the broader context" (Dagenais et al., 2017, p. 271). In these settings, although the goal is still bilingualism, it is assumed that bilingualism which involves mixing both languages will lead to minority language loss (Creese \& Blackledge, 2011; Cummins, 2017). This belief results in schools which teach primarily in French, with English as a subject area, and language boundaries between the two enforced (Creese \& Blackledge, 2011; Dagenais et al., 2017). In immersion, bilingualism is believed to develop through separate monolingual routes, despite research suggesting that students could benefit from learning about the many cognate relationships between French and English (Cummins, 2014a), and from the practical benefit of integrating curriculum objectives across both languages (Cummins, 2014a).

\section{"Heritage" Language Learning / International Language Education}

Heritage language learning or international language education programs typically use English and an additional language each for half of the school day (Manitoba Education and Training, 2011). This model promotes the retention of students' first language while simultaneously building English skills. Yet although linguistic diversity is an asset for the education of all students, it is not always publicly funded (Leung, 2016). The question of which bilingual programs are funded continues to fuel debate.

Despite commitment to multiculturalism through the 1971/1988 Multiculturalism Act (Lotherington, 2017) and the understanding that home languages play an important role in affirming identities and scaffolding learning (Stille \& Cummins, 2013), "we have been content to stand on the sidelines as observers while children's home languages slip away" (Cummins, 2014a, p. 9; Ntelioglou et al., 2014). The mandate of English-French provincial education "encourages, and in some cases, enforces, dropping learners' home languages at the door" (Lotherington, 2017, p. 5).

Linking home and school contexts is a practice that is encouraged within every programming model (Manitoba Education and Training, 2011), yet often heritage language learning happens within homes, cultural centres, and places of worship on weekends and after school without any connection between this learning and school (Moore, 2010). This is in direct opposition to research suggesting that students become more engaged with learning when their language, culture, and community are respected and represented by the school (Ntelioglou et al., 2014; Stille, 2015). In most schools and classrooms, cultural and linguistic diversity is only superficially engaged, "relegated to safe production in the home away from the economic Journal of Contemporary Issues in Education, 2019, 14(2), pp. 16-32. doi: 10.20355/jcie29370 ISSN 1718-4770 
necessities of the workplace and the social mandate of the classroom, performed in costume as historic theatre, and reified in the marketable consumables of the global gastronomic landscape" (Lotherington, 2017, p. 5).

Another challenge of heritage language learning is that these schools may present a "static, reified version of 'culture' and 'heritage', which may be remote from their students' experience" (Creese \& Blackledge, 2011, p. 1197). As Marshall and Toohey (2010) aptly point out, "children often participate in social worlds that differ from those of their parents" (p. 223), leading to the necessity for and creation of third spaces (Lotherington, 2013), which is different from both the parents' social world and the "mainstream" culture.

In sum, with any programming model, a realistic view is needed that includes acknowledging limitations of teacher preparation and training, funding limitations, and limited access to EAL professionals and support workers. Although pull-out programs can benefit students, they are not without challenges and they are costly. With increasing numbers of diverse students in mainstream classrooms, what approaches can be taken to both aid EAL students in their language acquisition while simultaneously acknowledging the strengths and legitimacy of their heritage languages? I explore several pedagogical approaches below.

\section{Classroom and Pedagogical Approaches}

Pursuing evidence-based policies points teachers and researchers away from English-only zones and toward policies that promote multilingual practices within individual classrooms (Ntelioglou et al., 2014). Based on this evidence, "it's not possible to credibly deny the legitimacy of multilingual education for minority and marginalized groups of students" (Cummins, 2014b, 2:05). Below I will highlight practical ways teachers and researchers have implemented multilingual, multicultural practices within schools and mainstream classrooms.

\section{Translanguaging}

Translanguaging (García, 2007) or "flexible bilingualism" (Creese \& Blackledge, 2011), is the result of removing separation between two languages, instead using both languages simultaneously. It leads away from a "focus on languages as distinct codes, to a focus on the agency of individuals in a school community engaging in using, creating and interpreting signs to communicate to multilingual audiences" (Creese \& Blackledge, 2011, p. 1197). The interactions between languages are complex and dynamic, rather than simply transferring from one language to another (Moore, 2010) or adding a monolingual language onto another (Cummins, 2017). Translanguaging repositions multilingualism as the norm and encourages students to use the "totality of their linguistic resources in an integrated way rather than compartmentalizing these resources into separate linguistic silos" (Cummins, 2017, p. 405).

Continuing instruction in multiple languages is more successful than transitional (sometimes called quick-exit) programming (Cummins, 2014a). In a review of 68 studies analyzing the relationship between first and second language development and literacy skills, it was clearly shown that first-language literacy skills confer advantages to language learning and that when language learning students have the opportunity to develop both languages simultaneously, they perform better than in English-only environments (August, Shanahan, \& Escamilla, 2009). Yet Journal of Contemporary Issues in Education, 2019, 14(2), pp. 16-32. doi: 10.20355/jcie29370 ISSN 1718-4770 
translanguaging is different from bilingualism as the "sum of two monolingualisms" (Cummins, 2017 , p. 405). It is both a "dynamic and integrated linguistic practice... and a pedagogical approach" (Cummins, 2017, p. 405).

Developing literacy in more than one language has cognitive and linguistic advantages (Cummins, 2014a). Advantages include an increase in awareness of language (metalinguistic awareness), enhanced executive control, and an easier time studying additional languages (Cummins, 2014a). For example, developing literacy in multiple languages can increase understanding how language systems operate, including comparing physical properties like direction of reading, and cultural properties like how to hold a pen (Moore, 2010). Beyond teaching for transfer, or teaching for meta-linguistic awareness, bi-/multilingualism is an advantage in today's global world (August et al., 2009). Encouraging translanguaging is not useful only so that students perform better in English, but so that they can develop the cognitive and linguistic advantages of full bilingualism and biliteracy (August et al., 2009).

This view may be restricted in schools at the policy level, such as the "one-teacher, onelanguage" policy adopted by some immersion schools (Cummins, 2017; Dagenais et al., 2017), or it may be individually restricted within classrooms by teachers who separate students who speak the same language by use of a seating chart, require students to work independently without helping one another, forbid copying each other's work, forbid orally repeating each other, and forbid borrowing materials from one another (Toohey, 1998).

As a linguistic practice, students make choices about which language to use, showcasing newcomer students as not simply language learners but as emerging bilinguals who bring a rich repertoire of assets and resources that they can use to learn and navigate school (Naqvi, 2015). Rather than separating monolingual codes, translanguaging acknowledges that multilingualism is fluid, not fixed, and that speakers/writers "present themselves and their views in a particular way, not only accomplishing successful referential communication goals but also reflecting the person's fashioned identity" (Atkinson et al., 2016, p. 26).

Educational practices may still be operating on a model that views languages as separate and considers home languages as interferences or unwanted influences (Dagenais et al., 2017). A more accurate model involves a common underlying proficiency with the languages overlapping and interdependent, with more commonalities between the languages than previously assumed (Cummins, 2014b). The view that languages are not "separate entities with impermeable boundaries" but are rather "fluid and interdependent (Dagenais et al., 2017, p. 264) points to the need for practices that view linguistic flexibility as an "indicator of the knowledge multilinguals have of languages in their environment and their skill in reading social situations" (Dagenais et al., 2017, p. 266).

In practice, it is highly unlikely that a teacher will have mastery of all the linguistic abilities of the students in the classroom. Particularly for monolingual teachers, putting translanguaging into practice is difficult, especially for assessment (Dagenais et al., 2017). Ways that teachers have addressed this is by leveraging the knowledge of parents, community members, online communities, or other multilingual students in the school or classroom, and by implementing tools such as Google Translate (Lotherington, 2013). 


\section{Content-Based Instruction / Content and Language Integrated Learning}

Content-based instruction (CBI) is based on the belief that the "best way to learn a language is to use a language" (Creese \& Blackledge, 2011, p. 1200). Rather than focusing on language as a subject, this model uses the language to explore topics within the curriculum such as math, science, or social studies, with the goal of simultaneously promoting language acquisition. A similar approach, more common in Europe but now also taken up in some Latin American and Asian countries, is termed Content and Language Integrated Learning (CLIL), though CLIL is more explicit in deeming both the language learning and the content learning as equally important goals (Coyle, Hood, \& Marsh, 2010). In both models, the language learning and the content learning happen simultaneously.

Teachers may use strategies to modify the language to make it more accessible. For example, teachers can make use of strategies such as using visual aids, articulating speech carefully, providing information in multiple ways, repeating, or having students volunteer to translate (Haneda \& Wells, 2012). Teachers may also use team-teaching strategies, where one teacher focuses on language and the other on the content (Banegas, 2011).

The strengths of CBI are that transfer of concepts occurs across languages, along with cognitive and linguistic strategies, specific linguistic elements, and phonological awareness (Cummins, 2014b). Cross-linguistic transfer is not only valuable for developing literacy when the languages are similar, but exploring contrasting elements of language is also valuable, as demonstrated in Moore's study of young Chinese children (2010). These children, aged 6-7, could explain differences and similarities between three languages (Chinese, French, and English) with a high degree of metalinguistic awareness. If it were possible to ensure that all else was equal, "the more extensive, complex, and multilingual the contexts of interaction become over time, and the more enduring learners' participation is in them, the more complex and enduring their multilingual repertoires will be" (Atkinson et al., 2016, p. 29). The topical approach may also be useful to promote engagement for students who are not interested in learning the language but are interested in the content or theme.

Challenges include lack of teacher preparation, curriculum constraints, lack of multicultural content in a Eurocentric curriculum, and standardized assessment that does not take linguistic proficiency into account. Content teachers may struggle to know how to explain abstract concepts in accessible language, or how to use first language resources to scaffold learning (Cañado, 2018). In addition, learners who have not reached a threshold level of language proficiency may not benefit from this approach. In team-teaching contexts, collaboration is also noted as a key concern (Cañado, 2018; Isidro, 2018).

\section{Multiliteracies}

The Multiliteracies Pedagogy project began in 2003 and aimed at rewriting traditional stories using multimodal and multilingual ways of representing knowledge (Lotherington, 2013; Ntelioglou et al., 2014). Children do not only develop literacy with books but through a variety of modes and digital connections (Marshall \& Toohey, 2010), including "graphic, pictorial, audio, physical, and spatial patterns of meaning" (Atkinson et al., 2016, p. 22). Although children arrive at school already well-versed in multiple competencies including cultural stories, Journal of Contemporary Issues in Education, 2019, 14(2), pp. 16-32. doi: 10.20355/jcie29370 ISSN 1718-4770 
social relationships, and worlds beyond their physical locations, schools largely ignore the multimodality of students' lives (Marshall \& Toohey, 2010). Multimodality refers to communication in the broadest sense, which may employ "multiple modes which may realize meanings that complement, extend, and/or contradict each other" (Early, Kendrick, \& Potts, 2015, p. 448). Modes can be any resource employed for making meaning, such as "image, gaze, gesture, movement, music, speech and sound-effect" (Early et al., 2015, p. 448).

Using multiliteracies, teachers and researchers can promote literacy, link out-of-school and school learning, draw on multiple modes of textuality, and incorporate students' funds of knowledge (Cummins, 2011; Marshall \& Toohey, 2010). Emerging new technologies can be used for language learning, including mobile devices, game-based learning, and others (Atkinson et al., 2016). Multiliteracies can also create third spaces, into which all languages are welcomed, cross-curricular questions can be explored, and multimedia texts can be created and used (Lotherington, 2013). Changing classroom dynamics through practices which encourage multilingualism and multimodality causes students to position themselves as experts, increases their literacy investment, and their engagement and learning (Ntelioglou et al., 2014). The goal of multiliteracies education is to promote fluency and literacy in both languages, not to simply allow a transitional period of first language use, with the goal of fluency and literacy in the second language (Cummins, 2014b). Multiliteracies aims to broaden the definition of literacy to include multiple languages, multiple literacies, and multiple modalities (Ntelioglou et al., 2014).

Challenges with multiliteracies involve availability of teachers, constraints of classroom materials, assessment challenges, and difficulty for some students to access subject-specific vocabulary in their first language (Cummins, 2014b). Teachers cannot teach every language, as the constraints on time and curriculum are real. However, multilingual inclusion can be meaningful in creating welcoming spaces for diverse students (Lotherington, 2017).

\section{Dual Language Books}

Under the leadership of Dr. Rahat Naqvi, the Dual Language Reading Project aimed at increasing language awareness, which she defines as, "an increased perception of how language is noticed and includes talking about language" (Naqvi, 2015, 19:14). The purpose of dual language books is to authentically integrate English language learners and mainstream students, to increase awareness of languages, cultures, and metalinguistics, and to provide alternative entry points within curriculum frameworks (Naqvi, 2015). This project demonstrated the principle that "inclusive teaching holds benefits for all children" (Chumak-Horbatsch, 2012, p. 4).

Dual language texts have been used by multiple teachers and researchers (Chumak-Horbatsch, 2012; Cummins, 2011; Dagenais et al., 2017), all of which demonstrate the potential of multilingualism within the classroom. Using stories in both a students' home language and English can improve their language acquisition (Dagenais et al., 2017), but it also helps students from English-speaking backgrounds (Naqvi, 2015). It can lead to curiosity about parents' or grandparents' languages, and can result in discussions about the similarities and differences across languages (Dagenais et al., 2017; Ntelioglou et al., 2014).

One of the challenges of this practice is for monolingual teachers to be able to confidently use dual language literature, which can be done by drawing on the resources of the community, Journal of Contemporary Issues in Education, 2019, 14(2), pp. 16-32. doi: 10.20355/jcie29370 ISSN 1718-4770 
families, or other students in the schools. Resources can also be accessed online (Lotherington, 2013). Another challenge with dual-language books, both with books already published in multiple languages (Naqvi, 2015) and with books created by the students (Dagenais et al., 2017), is that assessment can be difficult. Teachers feel that there is a conflict between the individualized nature of assessment and with the amount of help students receive from family and the community. In addition, teachers do not feel qualified to evaluate students' productions, beyond giving positive feedback (Dagenais et al., 2017).

Further, there are challenges with the technical aspects of creating dual-language stories. For example, budgets may prohibit purchasing expensive technology, switching keyboards between scripts may only be available for some languages but not all, and not all languages or modes (such as emoticons) may be available (Dagenais et al., 2017).

\section{Identity Texts}

While dual language books may feature any story, identity texts (Cummins \& Early, 2011) are student-created stories that focus on linking "identity affirmation and literacy" (Ntelioglou et al., 2014 , p. 4). Creating student-led bilingual texts that showcase ability in both languages is a powerful way to affirm identity, scaffold meaning, connect to students' lives, activate background knowledge, and extend language (Cummins \& Early, 2011; Early et al., 2015; Ntelioglou et al., 2014; Stille \& Cummins, 2013). Identity texts "hold a mirror up to students in which their identities are reflected back in a positive light" (Cummins, 2011, p. 4). Through the use of digital technology, the stories may then be published and shared with a broader audience (Stille \& Cummins, 2013).

It is not only EAL students who benefit from the creation of these texts, however, as the stories generated may challenge existing narratives (Stille, 2015) or may contradict Western teachers' understandings of what is considered appropriate for children (Marshall \& Toohey, 2010), leading to increased discussion and learning opportunities for all. It also highlights diversity within cultural groups, not just between cultures, as demonstrated by differences brought to the surface between a more liberal Muslim girl and her conservative Muslim classmates (Stille, 2015). This affirms a practice that theorizes culture as dynamic, rather than a unitary, bounded classification (Marshall \& Toohey, 2010, p. 222).

Education that includes both or multiple languages must affirm the identities of the students academically, cognitively, and personally (Cummins, 2014b). It cannot separate the students' lived experiences from language teaching and learning (Stille, 2015). Identity texts prompt students to share their "intellectual, literary, artistic, and multilingual talents in ways that challenge the devaluation of their cultures and identities in the school and wider society" (Cummins, 2011).

\section{Future Directions}

\section{Supporting Students Throughout the Journey}

Although language learners may only take one or two years to become conversationally adept (Cummins, 2011), they typically require at least five years or longer to attain grade expectations in language and literacy skills, in part because they are catching up to a constantly moving target Journal of Contemporary Issues in Education, 2019, 14(2), pp. 16-32. doi: 10.20355/jcie29370 ISSN 1718-4770 
and also because of the complexity and infrequent use of academic language (Cummins, 2014b). Accurate pronunciation can also mask "wobbly grounding in academic English" (Lotherington, 2017, p. 10), as conversational fluency and academic proficiency are different (Cummins, 2011). For this reason, it is important to recognize that although a student may demonstrate proficiency in communication, or may have strong academic skills, that student may need more support as academic language demands increase (Manitoba Education and Training, 2011). The goal of EAL programs in schools should not be to transition students to mono-linguistic classrooms as quickly as possible since the effects of bilingual programming and first language programming are cumulative and beneficial. Rather, the goal should be to maintain bi-/multilingual programming as long as reasonably possible, given the constraints of curriculum materials and teacher availability (August et al., 2009).

\section{Multilingualism: Detriment, Bridge, or Destination?}

It is a dramatic shift to go from considering multilingualism a detriment to English acquisition to viewing multilingual practices as scaffolds which ultimately support English language development, to then viewing multilingual practices as an end goal in and of themselves. In many classrooms, bi-/multilingual practices are still restricted. Understanding the cognitive and linguistic benefits of practices like translanguaging, multiliteracies, dual language books, and identity texts may be readily adopted when teachers and administrators understand their benefit for academic achievement of all students. But they should not be adopted simply for raising achievement scores in English, as newcomer students may simultaneously occupy citizenship in countries reflecting multiple languages, may be moving between countries, and may be using language to navigate flexible identities and roles. In today's world, this fluid, dynamic, global citizenship displayed by multilingualism is a strength to encourage in all students, rather than being presented as a stepping stone to English monolingualism.

\section{Shifting Ideals of Teacher Competency}

Even if all teachers and administrators could agree that multilingualism is a benefit for all, the practical aspects remain a challenge. Funding is limited to hire EAL professionals that could meet the needs of students, and teacher preparation programs have been slow to adopt changes that would adequately prepare teachers for linguistic diversity. Although schools may support multilingualism in principle, it may take a great deal of support and encouragement to see those principles put into practice. There is a "dire need" (August et al., 2009, p. 444) for teacher development and training both to change teachers' and administrators' beliefs and attitudes towards language learning students and also to provide strategies and approaches that will be practical and able to be implemented within realistic budgets and limitations.

A shift is required that reconceptualizes the monolingual, monocultural "ideal teacher" towards an ideal teacher who is multicultural and multilingual. This teacher would be able not only to represent diverse students in the school but to teach from the perspective that multiple ways of knowing, expressing, and representing knowledge are not only acceptable but encouraged. As with any such shift in power, there will be challenges. Removing barriers for diverse teachers (Schmidt, 2015) is one step along the path toward reconceptualizing the "ideal teacher." 


\section{Foundations for Future Directions}

Acknowledging the dynamically interconnected nature of languages, recognizing that competencies in these languages may not develop in tandem, understanding that all students benefit from multilingual practices, and developing metalinguistic awareness within classrooms (Ntelioglou et al., 2014) are foundations upon which promising practices, policies, and programs can be built. These foundations place the student as the focus of any interaction, rather than the language (Creese \& Blackledge, 2011), and encourage students to use the multilingual repertoires available to them in order to express themselves.

\section{References}

Ali, M. A. (2008). Second-generation youth's belief in the myth of Canadian multiculturalism. Canadian Ethnic Studies, 40(2), 89-107. https://doi.org/10.1353/ces.2010.0017

Atkinson, D., Byrnes, H., Doran, M., Duff, P., Ellis, N. C., Hall, J. K., ... Tarone, E. (2016). A Transdisciplinary Framework for SLA in a Multilingual World. 100(S1), 19-47. https://doi.org/10.1111/modl.12301

August, D., Shanahan, T., \& Escamilla, K. (2009). English language learners: Developing literacy in second-language learners - Report of the national literacy panel on languageminority children and youth. Journal of Literacy Research, 41(4), 432-452. https://doi.org/10.1080/10862960903340165

Banegas, D. L. (2011). A review of "CLIL: Content and language integrated learning": by D. Coyle, P. Hood, and D. Marsh. Language and Education, 25(2), 181-185. https://doi.org/10.1080/09500782.2010.539045

Cañado, M. L. P. (2018). Innovations and challenges in CLIL teacher training. Theory Into Practice, 57(3), 1-10. https://doi.org/10.1080/00405841.2018.1492238

Chumak-Horbatsch, R. (2012). Linguistically appropriate practice: A guide for working with young immigrant children (2 edition). Ontario, Canada: University of Toronto Press, Higher Education Division.

Coyle, D., Hood, P., \& Marsh, D. (2010). CLIL: Content and language integrated learning. Cambridge: Cambridge University Press.

Creese, A. \& Blackledge, A. (2011). Separate and flexible bilingualism in complementary schools: Multiple language practices in interrelationship. Journal of Pragmatics, 43(5), 1196-1208. https://doi.org/10.1016/j.pragma.2010.10.006

Cummins, J. (2011). Literacy engagement: Fueling academic growth for English learners. The Reading Teacher, 65(2), 142-146. https://doi.org/10.1002/TRTR.01022

Cummins, J. (2014a). To what extent are Canadian second language policies evidence-based? Reflections on the intersections of research and policy. Frontiers in Psychology, 5. https://doi.org/10.3389/fpsyg.2014.00358

Cummins, J. (2014b). Multilingual education for social justice: From coercive to collaborative relations of power. Retrieved from https://www.youtube.com/watch?v=-P2cJa92vg8

Cummins, J. (2017). Teaching minoritized students: Are additive approaches legitimate? Harvard Educational Review, 87(3), 404-425. https://doi.org/10.17763/1943-504587.3.404

Cummins, J., \& Early, M. (2011). Identity texts: The collaborative creation of power in multilingual schools. Trentham Books Ltd.

Journal of Contemporary Issues in Education, 2019, 14(2), pp. 16-32. 
Dagenais, D., Toohey, K., Bennett Fox, A., \& Singh, A. (2017). Multilingual and multimodal composition at school: "ScribJab" in action. Language and Education, 31(3), 263-282. https://doi.org/10.1080/09500782.2016.1261893

Duff, P. A. (2015). Transnationalism, multilingualism, and identity. Annual Review of Applied Linguistics, 35, 57-80. https://doi.org/10.1017/S026719051400018X

Early, M., Kendrick, M., \& Potts, D. (2015). Multimodality: Out from the margins of English language teaching. TESOL Quarterly, 49(3), 447-460. https://doi.org/10.1002/tesq.246

Freire, P. (1996). Pedagogy of the oppressed (revised edition). London: Penguin Books.

García, O. (2007). Foreward. In S. Makoni \& A. Pennycook (Eds.), Disinventing and reconstituting languages (pp. xi-xv). Clevedon: Multilingual Matters.

García, O. (2008). Bilingual education in the 21st century: A global perspective (1st ed.). Malden, MA; Oxford: Wiley-Blackwell.

Gorski, P. C. (2008). Good intentions are not enough: A decolonizing intercultural education. Intercultural Education, 19(6), 515-525. https://doi.org/10.1080/14675980802568319

Government of Canada, S. C. (2017, August 17). The daily - An increasingly diverse linguistic profile: Corrected data from the 2016 Census. Retrieved September 20, 2018, from https://www150.statcan.gc.ca/n1/daily-quotidien/170817/dq170817a-eng.htm

Haneda, M., \& Wells, G. (2012). Some key pedagogic principles for helping ELLs to succeed in school. Theory Into Practice, 51(4), 297-304. https://doi.org/10.1080/00405841.2012.726059

Howard, G. R. (2016). We can't teach what we don't know (3 edition). New York: Teachers College Press.

Isidro, X. S. (2018). Innovations and challenges in CLIL implementation in Europe. Theory Into Practice, 57(3), 185-195. https://doi.org/10.1080/00405841.2018.1484038

Janks, H. (2004). The access paradox. English in Australia, (139), 33.

Kanno, Y. (1999). Comments on Kelleen Toohey's “"Breaking uhem Up, taking them away': ESL students in grade 1." TESOL Quarterly, 33(1), 126-132. https://doi.org/10.2307/3588195

Krashen, S. D. (1982). Principles and practice in second language acquisition (1st ed..). Oxford: Pergamon, Pergamon Press.

Ladson-Billings, G. (1995). Toward a theory of culturally relevant pedagogy. American Educational Research Journal, 32(3), 465-491. https://doi.org/10.3102/00028312032003465

Leung, C. (2016). English as an additional language - a genealogy of language-in-education policies and reflections on research trajectories. Language and Education, 30(2), 158174. https://doi.org/10.1080/09500782.2015.1103260

Lotherington, H. (2013). Creating third spaces in the linguistically heterogeneous classroom for the advancement of plurilingualism. TESOL Quarterly, 47(3), 619-625. https://doi.org/10.1002/tesq.117

Lotherington, H. (2017). Elementary school language and literacy education for civic engagement: An evolving playbook for postmodern times. Language and Literacy, 19(3), 4. https://doi.org/10.20360/G2M952

Manitoba Education and Training. (2011, June). Curriculum framework for English as an additional language (EAL) and literacy, academics, and language (LAL) programming. Retrieved October 8, 2018, from https://www.edu.gov.mb.ca/k12/cur/eal/framework/index.html

Journal of Contemporary Issues in Education, 2019, 14(2), pp. 16-32. 
Marshall, E., \& Toohey, K. (2010). Representing family: Community funds of knowledge, bilingualism, and multimodality. Harvard Educational Review, 80(2), 221-242. https://doi.org/10.17763/haer.80.2.h3446j54n608q442

Moore, D. (2010). Multilingual literacies and third script acquisition: Young Chinese children in French immersion in Vancouver, Canada. International Journal of Multilingualism, 7(4), 322-342. https://doi.org/10.1080/14790718.2010.502231

Naqvi, R. (2015). The evolving face of literacy: What role can languages play in mainstream classrooms? Retrieved from https://www.youtube.com/watch?v=SWw9LVZtods

Ntelioglou, B. Y., Fannin, J., Montanera, M., \& Cummins, J. (2014). A multilingual and multimodal approach to literacy teaching and learning in urban education: A collaborative inquiry project in an inner city elementary school. Frontiers in Psychology, 5. https://doi.org/10.3389/fpsyg.2014.00533

Schmidt, C. (2015). Herculean efforts are not enough: Diversifying the teaching profession and the need for systemic change. Intercultural Education, 26(6), 584-592. https://doi.org/10.1080/14675986.2015.1109776

Statista. (2018). Enrollment in public elementary and secondary schools 2000-2016. Retrieved October 5, 2018, from Statista website: https://www.statista.com/statistics/449105/enrollment-in-public-elementary-andsecondary-schools-in-canada/

Stille, S. (2015). Identity as a site of difference: Toward a complex understanding of identity in multilingual, multicultural classrooms. Intercultural Education, 26(6), 483-496. https://doi.org/10.1080/14675986.2015.1109777

Stille, S., \& Cummins, J. (2013). Foundation for learning: Engaging plurilingual students' linguistic repertoires in the elementary classroom. TESOL Quarterly, 47(3), 630-638. https://doi.org/10.1002/tesq.116

Toohey, K. (1998). "Breaking them up, taking them away": ESL students in grade 1. TESOL Quarterly, 32(1), 61-84. https://doi.org/10.2307/3587902

Waterhouse, S. (2004). Deviant and non-deviant identities in the classroom: Patrolling the boundaries of the normal social world. European Journal of Special Needs Education, 19(1), 69-84. https://doi.org/10.1080/0885626032000167151 